\title{
Assessing the hydrodynamic boundary conditions for risk analyses in coastal areas: a stochastic storm surge model
}

\author{
T. Wahl, C. Mudersbach, and J. Jensen \\ Research Institute for Water and Environment, University of Siegen, Germany \\ Received: 9 August 2011 - Accepted: 19 September 2011 - Published: 4 November 2011
}

\begin{abstract}
This paper describes a methodology to stochastically simulate a large number of storm surge scenarios (here: 10 million). The applied model is very cheap in computation time and will contribute to improve the overall results from integrated risk analyses in coastal areas. Initially, the observed storm surge events from the tide gauges of Cuxhaven (located in the Elbe estuary) and Hörnum (located in the southeast of Sylt Island) are parameterised by taking into account 25 parameters (19 sea level parameters and 6 time parameters). Throughout the paper, the total water levels are considered. The astronomical tides are semidiurnal in the investigation area with a tidal range $>2 \mathrm{~m}$. The second step of the stochastic simulation consists in fitting parametric distribution functions to the data sets resulting from the parameterisation. The distribution functions are then used to run Monte-Carlo-Simulations. Based on the simulation results, a large number of storm surge scenarios are reconstructed. Parameter interdependencies are considered and different filter functions are applied to avoid inconsistencies. Storm surge scenarios, which are of interest for risk analyses, can easily be extracted from the results.
\end{abstract}

\section{Introduction and objectives}

Performing integrated risk analyses is a crucial task for coastal managers and engineers and becomes even more important in times of a warming climate, which potentially leads to changes of mean sea level heights, storminess or the wave climate. At the same time, the concentration of people living and assets located in coastal areas is rapidly increasing and is expected to continue to grow dramatically in the future (McGranahan et al., 2007; Nicholls et al., 2011). Today

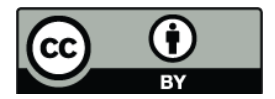

Correspondence to: T. Wahl (thomas.wahl@uni-siegen.de) millions of people and billions of assets are threatened by inundation caused by mean sea level changes and first of all by storm surge impacts.

The European Union (EU) has recently passed a directive "on the assessment and management of flood risks (2007/60/EC)" (EU, 2007). The directive requires the EU member states to investigate flood risks for potentially affected areas (inland and coastlines). For coastal areas, different storm surge scenarios have to be considered to map the flood extent. At least three different scenarios (with low, medium and high probabilities of occurrence) should be taken into account for the analyses. The preparation of flood risk maps includes the estimation of the adverse consequences (number of affected inhabitants, types of economic activities in the affected areas, pollution etc.). Based on this information, flood risk management plans have to be established. The quantification of potential losses in the hinterland as well as the estimation of failure probabilities of existing flood defence structures is not provided. However, this is what has to be done when appling risk based design methods or performing intergrated risk analyses, respectively, which have gained more importance in river and coastal engineering in recent years (e.g. FLOODsite, 2009; Schumann, 2011). In Germany, the joint research project XtremRisK (www.xtremrisk.de) was launched in 2008 to perform pilot studies (i.e. integrated risk analyses) for two investigation areas in the German Bight (Sylt Island and Hamburg) (Oumeraci et al., 2009; Burzel et al., 2010).

A widely used approach to conduct integrated risk analyses is based on the Source-Pathway-Receptor-Concept (SPRConcept; e.g. Oumeraci, 2004) as shown in Fig. 1. First, the risk sources are analysed before failure probabilities of the flood defence structures are calculated. Breach models (for dykes or dunes) are applied to identify the initial conditions for flood propagation and finally, potential losses in the hinterland are quantified. The present paper focuses on the first part, i.e. the investigation of the risk sources (here:

Published by Copernicus Publications on behalf of the European Geosciences Union. 


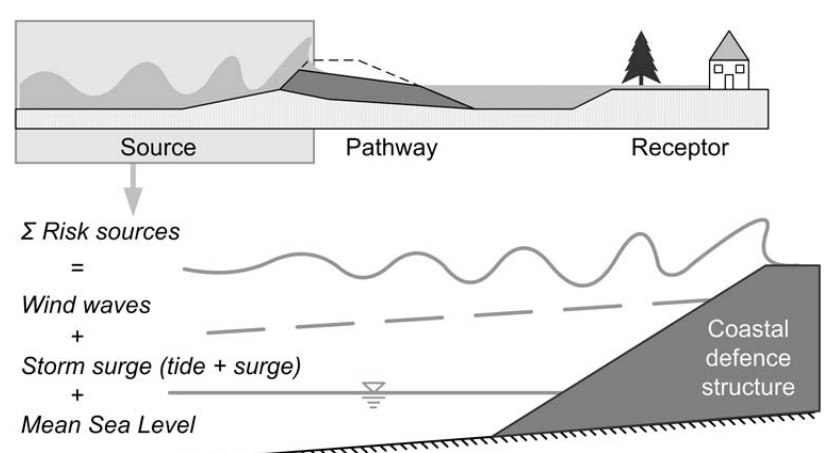

Fig. 1. Source-Pathway-Receptor Concept for risk analyses and relevant risk sources for coastal areas.

first of all, storm surges). From Fig. 1 it can be seen that different risk sources have to be taken into account for flood risk analyses in coastal areas. Mean sea level represents a quasi-static loading factor for coastal defence structures, as possible changes occur comparably slow and adaptation strategies can be planned. Wahl et al. (2010a, 2011a) recently conducted a detailed analysis of observed mean sea level changes in the German Bight. Storm surges and wind waves, which may coincide due to meteorological forcing, represent dynamic loading factors leading to high water levels for shorter time periods. Throughout this paper, the term "storm surges" describes extreme still water levels (i.e. waves not included) that arise from the combination of astronomical tides and a meteorologically induced surge component. Investigations on long-term changes of storm surges in the German Bight have recently been undertaken by Mudersbach et al. (2011).

It is necessary to consider a large number of storm surge scenarios for a scenario-based risk analysis, as outlined by Fig. 2. Initially, a risk curve (as shown in Fig. 2, left) has to be estimated before its integration leads to the overall flood risk. The approximation of a risk curve requires a larger number of events to be considered as sampling points (Fig. 2 contains only four events for presenting purposes). Figure 2 (right) highlights that storm surge scenarios with extremely high water levels are not relevant for an integrated risk analysis because the exceedance probabilities $P_{\mathrm{e}}$ of such storm surge events and thus the related probabilities of flooding $P_{\text {flood }}$ are approximately zero. At the same time, storm surge scenarios with low water levels can also be neglected, as the potential losses $D$ caused by such events are approximately zero.

To derive a sufficient number of relevant storm surge scenarios as input data for risk analyses, different methods are available and have been considered in former studies. $\mathrm{Nu}$ merical hydrodynamic models can be used (e.g. Jensen et al., 2006; Mudersbach and Jensen, 2009) as well as empirical approaches (e.g. Gönnert et al., 2010). Both methods are very time consuming and therefore restrict the number
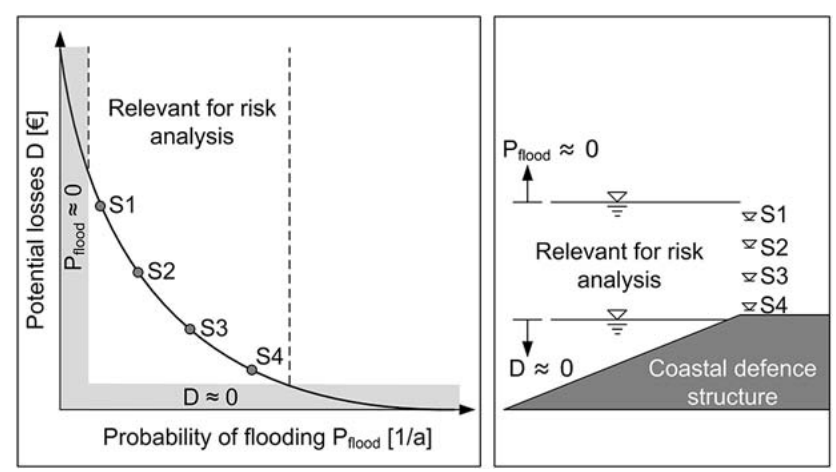

Fig. 2. Risk curve (left) and relevance of different storm surge scenarios with different water level heights for risk analyses in coastal areas (right).

of scenarios which can be generated. Furthermore, it is important to take into account storm surges with different characteristics. This does not only include the storm surge water level height, but also the temporal evolution of the storm surge water levels (i.e. the time-dependent behaviour of the water levels) or the duration of the storm surge events (see e.g. Cai et al., 2008; Wahl et al., 2011b). In this paper, an approach to stochastically simulate a large number of storm surge scenarios (here: 10 million) is presented. Selected storm surge scenarios from the simulated results, which are relevant because of their characteristics, can directly be considered for risk analyses. Uncertainties are reduced by considering a larger number of scenarios. Further, the required computation time is comparable small. At the same time, the simulated storm surge events can be used as input data for statistical assessments (in addition to the observations), which also play an important role when performing integrated risk analyses. A multivariate statistical model based on Copula functions to jointly analyse selected storm surge and wave parameters is presented in a companion paper by Wahl et al. (2011b). In this companion study, the results presented here (i.e. stochastically simulated storm surge events) are considered as the data basis and joint exceedance probabilities are calculated (with and without wave conditions included).

Risk-based design methods and probability concepts in which stochastically simulated input variables are used have already been established in different fields (e.g. structural and mechanical engineering, hydrology etc.) (Ang and Tang, 2007; Reeve, 2010). Especially for designing dams or reservoirs, similar approaches to the one presented in this paper for coastal areas are widely used. The methodology considered, for example, by Klein (2009) or Bender and Jensen (2011) to stochastically simulate flood hydrographs, consists of similar computational steps. However, significant enhancements were necessary to account for the different systematic situations in coastal regions. The methodology to stochastically simulate storm surge scenarios was already 

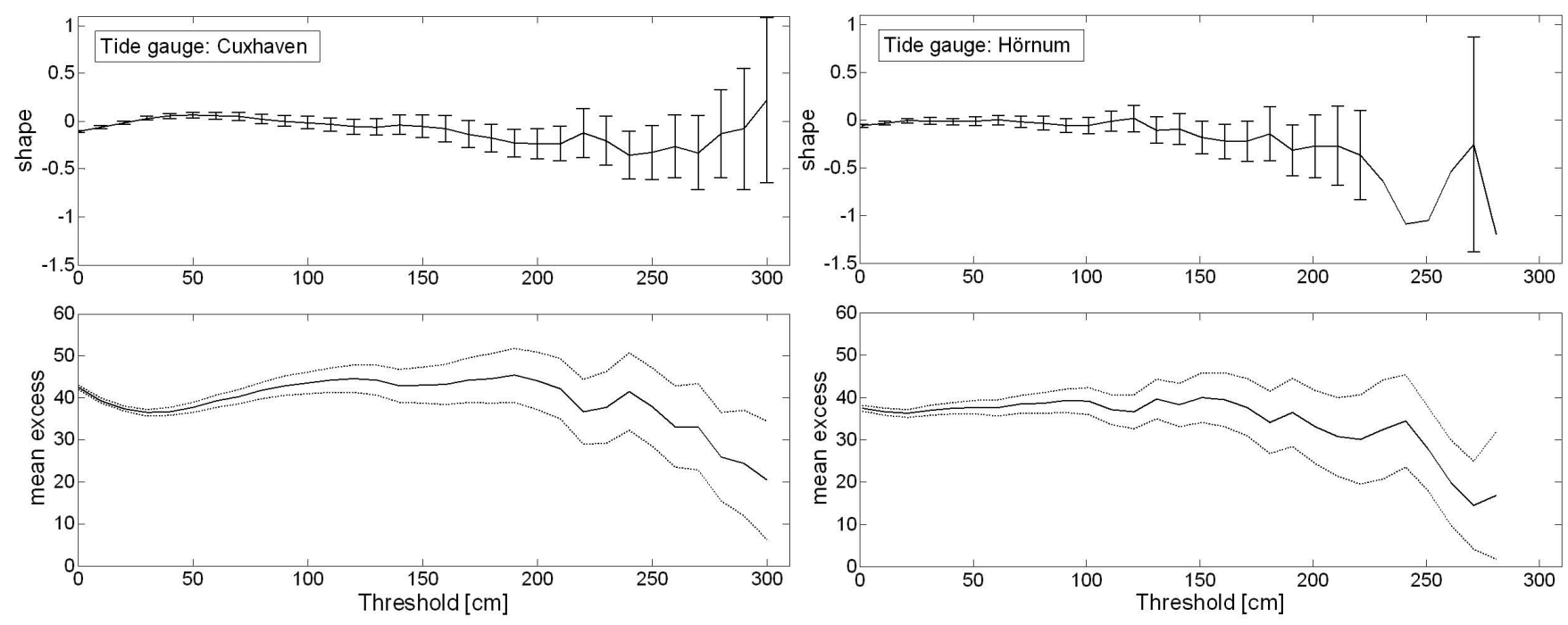

Fig. 3. Results of the Stability Method (top) and Mean Residual Life plots (bottom) with $95 \%$-confidence bounds to identify appropriate thresholds based on the tidal high water time series for the tide gauges of Cuxhaven (left) and Hörnum (right).

briefly described by Wahl et al. (2010b). The present paper provides detailed information about all relevant computational steps; the applicability of the model to different investigation areas (i.e. an island and an estuary) is tested and a validation section is included.

The paper is organised as follows: in Sect. 2 the considered data sets are introduced. The applied methodology is described in detail in Sect. 3. The key results are summarised and discussed in Sect. 4 and the paper closes with conclusions in Sect. 5.

\section{Data}

The following analyses are based on the available sea level observations from the tide gauges of Hörnum and Cuxhaven. Hörnum is located in the Southeast of Sylt Island (tide gauge location: $54^{\circ} 45^{\prime} 29^{\prime \prime} \mathrm{N}, 8^{\circ} 45^{\prime} 29^{\prime \prime} \mathrm{E}$ ) in the northeastern part of the German Bight. Cuxhaven is located in the Elbe estuary (tide gauge location: $53^{\circ} 52^{\prime} 04^{\prime \prime} \mathrm{N}, 8^{\circ} 43^{\prime} 03^{\prime \prime} \mathrm{E}$ ) in the southeastern part of the German Bight. The tidal regime is semi-diurnal and the mean tidal ranges for Cuxhaven and Hörnum are $2.97 \mathrm{~m}$ and $2.05 \mathrm{~m}$, respectively (estimated for the 19-yr period from 1990 to 2008). The tide gauges have been chosen as they provide long records and they are located in areas of special interest. Sylt Island is the biggest German North Sea island and a popular tourist destination. The island hosts valuable monetary and ecological assets and is very vulnerable to extreme storm surge events. In December 1990, a storm surge evoked by the low pressure system "Anatol" caused extensive erosion along major parts of the island's coastline. The tide gauge of Cuxhaven provides the longest record of all German gauges and is used as the reference station to assess the flood risk for the city of Hamburg, the only German megacity located in an estuary. The most devastating storm surge event along the German North Sea coastline over the last century occurred in February 1962. 340 people died (315 in Hamburg) and major parts of the city of Hamburg were flooded.

Considering the temporal behaviour of storm surge water levels, it is necessary to analyse high frequency observations (at least hourly data). The tide gauge of Hörnum has provided data from 1936 onwards (digital high frequency data since 1999, digital high and low waters and analogue tidal charts before 1999). Cuxhaven has provided continuous data from 1900 onwards (digital high frequency data since 1918, digital high and low waters and analogue tidal charts before 1918).

To identify storm surge events from the available tidal high water (HW) time series, a peak over threshold (POT) method is applied. When forecasting storm surges along the German North Sea coastline, the Federal Maritime and Hydrographic Agency (BSH) uses a threshold of $150 \mathrm{~cm}$ above mean tidal high water level (MHW) to separate storm surges from mean conditions (e.g. Wieland, 1990; www.bsh.de). Under present conditions, this equals a total water level of about $305 \mathrm{cmNN}$ for Cuxhaven and of about $253 \mathrm{cmNN}$ for Hörnum (where $\mathrm{cmNN}$ stands for $\mathrm{cm}$ above Normal Null, which is the German ordnance datum).

To select appropriate thresholds for extreme value analyses, Coles (2001) proposed two different methods, namely the Stability Method (STM) and Mean Residual Life (MRL) plots. Both methods have been applied here. In the STM, parameters of a Generalized Pareto distribution (GPD) are fitted to the available (and de-trended) data sets by considering 

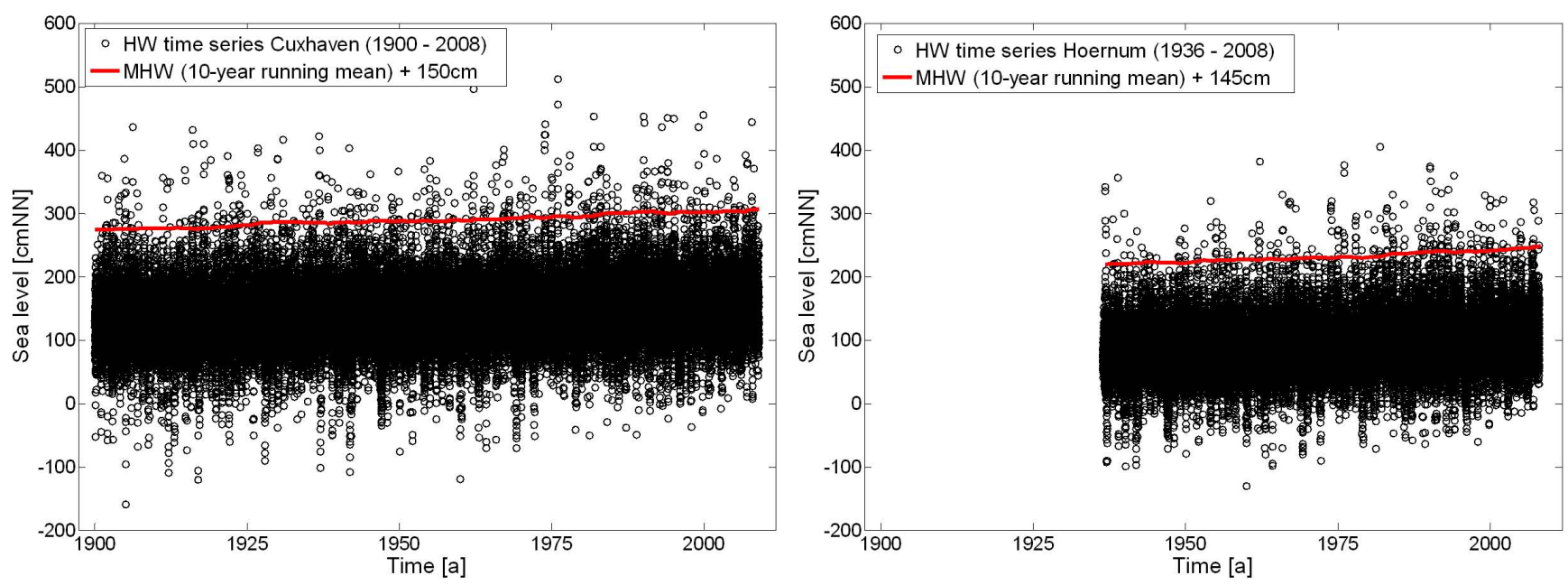

Fig. 4. Tidal high water (HW) time series for Cuxhaven (left) and Hörnum (right) with the estimated threshold time series.

different thresholds $u$. Figure 3 (top) shows the results for the shape parameter of the GPD (left: Cuxhaven, right: Hörnum) with $95 \%$-confidence bounds included (confidence bounds for Hörnum cannot be reliably calculated for large values of $u$ ). An appropriate threshold is assumed where the shape parameter is approximately constant. As it can be seen, an objective interpretation of the results is difficult. For Cuxhaven, the value of $150 \mathrm{~cm}$ above MHW appears to be a suitable choice, whereas the results for Hörnum suggest choosing a slightly smaller value. To create MLR plots, the values exceeding different thresholds $u$ are averaged (see Coles, 2001 for more information). Figure 3 (bottom) shows the results for Cuxhaven (left) and Hörnum (right). An appropriate threshold is assumed where the function starts to become approximately linear. Again, the results are not clear and the interpretation is even more complicated compared to the STM. Thus, thresholds of $u=150 \mathrm{~cm}$ above MHW for Cuxhaven (equals a total water level of $305 \mathrm{cmNN}$ under current conditions) and of $u=145 \mathrm{~cm}$ above MHW for Hörnum (equals a total water level of $248 \mathrm{cmNN}$ ) are chosen for the present study. Further methods to identify appropriate threshold values are described and discussed by Lang et al. (1999).

Figure 4 shows the available HW time series for Cuxhaven from 1900 to 2008 (left) and for Hörnum from 1936 to 2008 (right) and the estimated threshold time series. MHW is defined here as the 10-yr running mean of the observed HW to take into account long-term sea level changes. The number of threshold exceedances for Cuxhaven is 388 and 232 for Hörnum, due to the shorter time period that is involved.

As mentioned previously, it is necessary to take into account the temporal evolution of water levels during storm surge events in addition to the maximum storm surge water levels. Therefore, it is required to define storm surge scenarios not only in height but also in length or duration. The numbers of successive high tides exceeding the selected

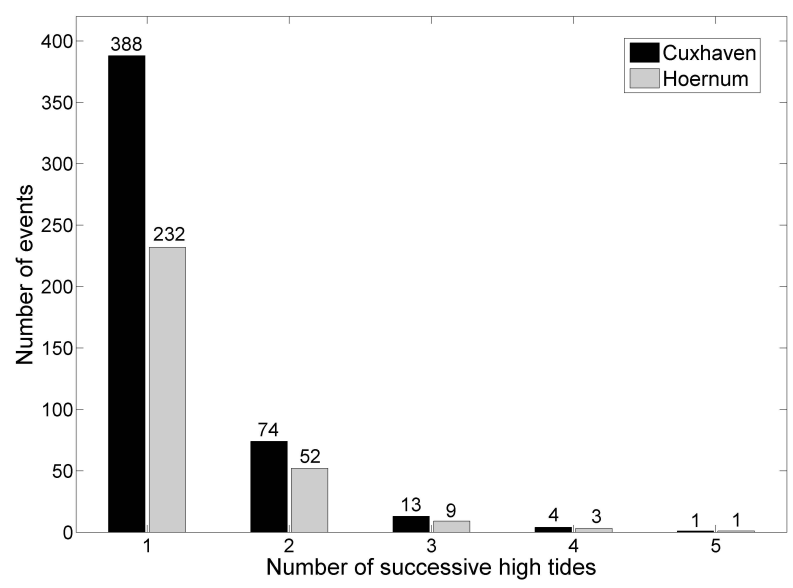

Fig. 5. Number of successive high tides exceeding the selected threshold values.

thresholds are shown in Fig. 5. In the majority of cases, the events last one or two tidal cycles. Four or five high tides in a row have rarely been observed in the past. Thus, three tides of the observed storm surge events (initial tide, main tide, follow-up tide; i.e. 1.5 days) are considered in the following. To assure independency, two storm surge events have to be at least $30 \mathrm{~h}$ apart from each other (referring to the time when the maximum water levels occur). This reduces the number of relevant events to 314 for Cuxhaven and 175 for Hörnum. Prior to 1918 for Cuxahen and 1999 for Hörnum, the events were digitized from the available analogue tidal charts for the present study. 


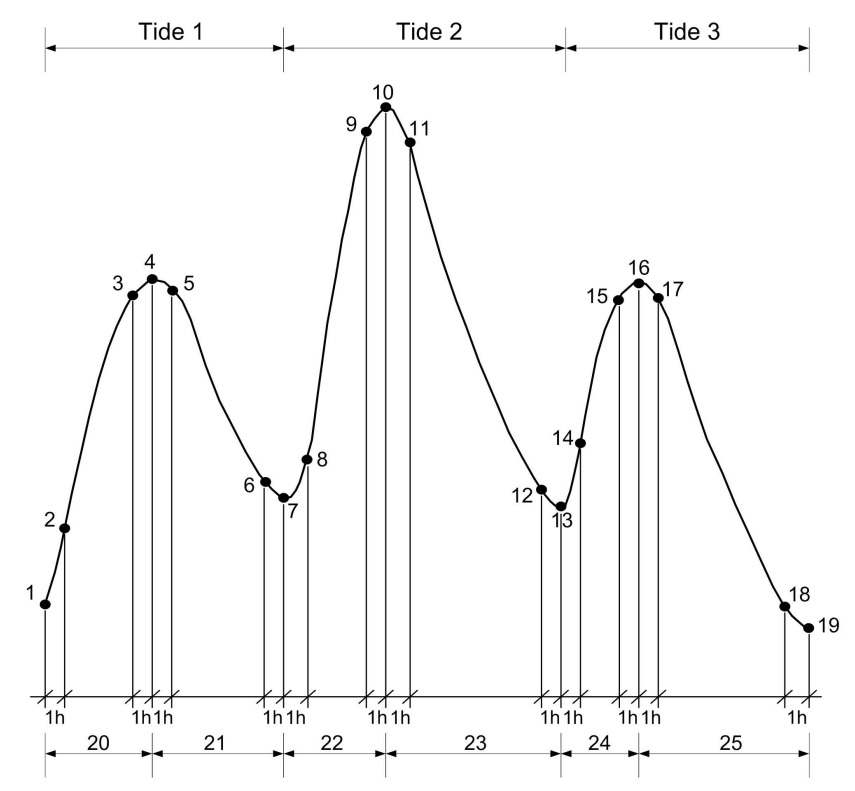

Fig. 6. Parameterisation scheme used to paramterise observed storm surge events consisting of thress tides.

\section{Method}

The method used to stochastically simulate synthetic storm surge scenarios consists of three computational steps, which are described in the following.

\subsection{Parameterisation of observed storm surge events}

Initially, the observed storm surge events are parameterised. As outlined in Sect. 1, the total water levels (arising from the combination of tides and surges) are taken into account instead of removing the deterministic tidal component before parameterising the residual surge component. This procedure is justified for the following reasons: (i) parameterisation of the surge residuals is much more complex and increases the uncertainties than parameterising the total water level time series as described below, (ii) the re-combination of randomly simulated surge curves with the deterministic tide requires either independency between the two components or a detailed understanding of the existing non-linear tide-surge interaction in the investigation area. Both are not the case for the German Bight. Therefore, the total water levels are considered throughout this study, as these are also relevant for coastal managers.

From sensitivity studies, it was found that a total number of 25 parameters is sufficient to capture the main characteristics of a storm surge event consisting of three tides. Figure 6 shows the 25 parameters, which are (i) the tidal high and low waters of the three tides comprising a storm surge event, (ii) the water levels one hour before and one hour after the high and low waters and (iii) the time periods between

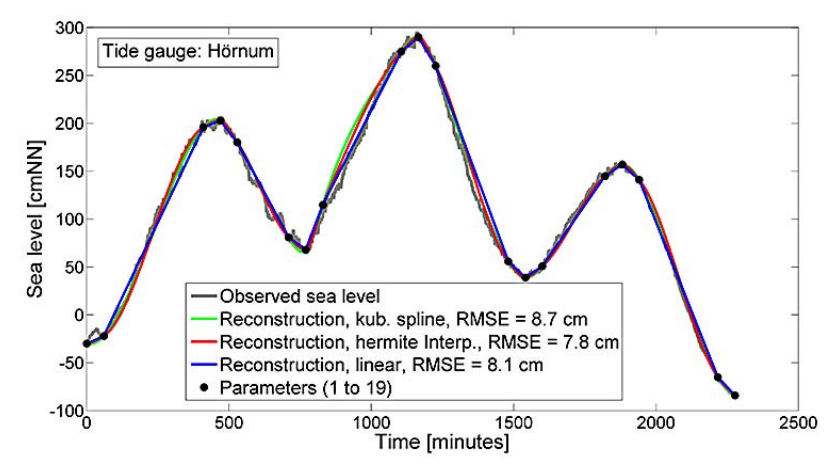

Fig. 7. Results from parameterising and reconstructing a selected storm surge event by applying different interpolation methods to reconstruct the observed storm surge curve.

two adjacent high and low waters. Parameters 1 to 19 represent sea level heights whereas parameters 20 to 25 are time parameters. The height parameters can all be expressed relative to parameter 10 (i.e. the maximum water level observed during the storm surge event). This means that parameters 1 , 4, 7, 13, 16 and 19 (tidal high and low waters) refer to parameter 10. Parameter 7, for example, is calculated by subtracting the observed tidal low water level (i.e. the absolute water level of parameter 7) from the maximum water level observed during the storm surge event (i.e. parameter 10). The parameters surrounding the tidal high and low waters refer to the particular peak water levels. Parameter 3, for example, is calculated by subtracting the water level which has been observed one hour before the high water (i.e. the absolute water level of parameter 3 ) from the tidal high water level (i.e. the absolute water level of parameter 4).

For the reconstruction of a storm surge curve based on the 25 parameters, three different methods are tested, namely linear interpolation, cubic spline interpolation, and piecewise cubic hermite interpolation. Figure 7 shows an example of the results from parameterising and reconstructing a selected storm surge event at the Hörnum tide gauge. The storm surge was induced by the extra-tropical cyclone "Tilo" that occurred in November 2007. The quality of the reconstruction results, considering the different interpolation methods, is evaluated by calculating root mean squared errors (RMSE). As it can be seen in Fig. 7, the estimated RMSEs are similar and all three methods lead to good results for the selected storm surge event. The smallest RMSE is achieved with the piecewise cubic hermite interpolation (also known as cspline; e.g. Kahaner et al., 1988). This was confirmed from parameterising and reconstructing all of the other observed storm surge events (i.e. 314 events for Cuxhaven and 175 events for Hörnum) using the three different interpolation methods.

Figure 8 shows the results of the parameterisation and reconstruction by applying piecewise cubic hermite interpolation for further storm surge events, four for Cuxhaven (left) 

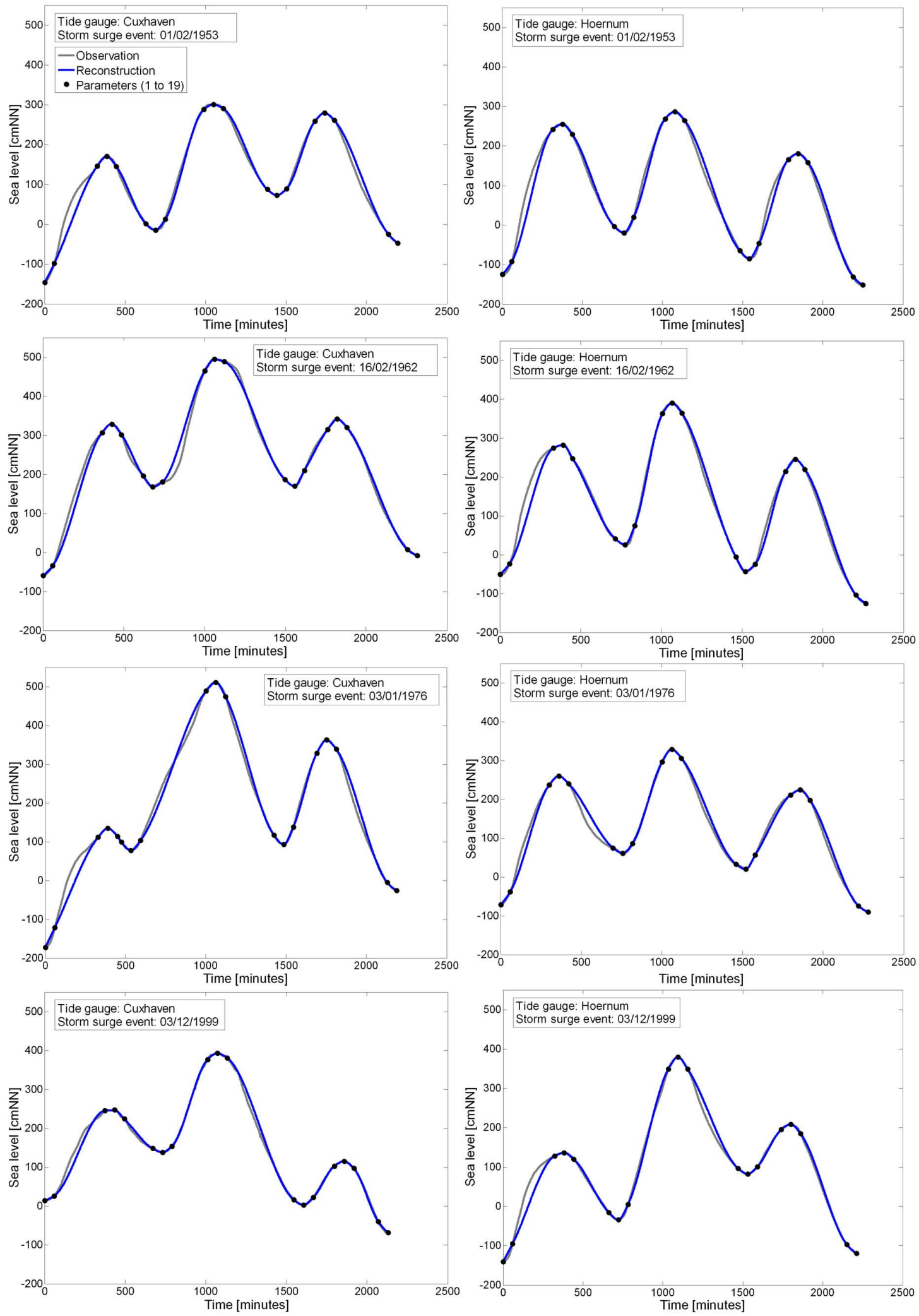

Fig. 8. Results from parameterising and reconstructing selected storm surge events observed at the tide gauges of Cuxhaven (left) and Hörnum (right). 
Table 1. Distribution functions considered in the present study to be fitted to the time series resulting from the parameterisation of the observed storm surge events.

\begin{tabular}{ll}
\hline Distribution & Equation \\
\hline Generalized Pareto & for $k \neq 0$ \\
& $\begin{array}{l}\mathrm{GP}(x)=1-\left(1+\frac{k(x-a)}{b}\right)^{\frac{-1}{k}} \\
\text { for } k=0 \\
\operatorname{GP}(x)=1-e^{\left(-\frac{x-a}{b}\right)}\end{array}$ \\
\hline LogNormal & $\operatorname{LogN}(x)=\frac{1}{b \sqrt{2 \pi}} \int_{0}^{x} \frac{1}{t} e^{-\frac{(\ln t-a)^{2}}{2 b^{2}}} d t$ \\
\hline Normal & $\mathrm{N}(x)=\frac{1}{b \sqrt{2 \pi}} \int_{-\infty}^{x} e^{\frac{-(t-a)^{2}}{2 b^{2}}} d t$ \\
\hline Weibull & $\mathrm{WBL}(x)=1-e^{-\left(\frac{x}{b}\right)^{k}}$ \\
\hline
\end{tabular}

and four for Hörnum (right). The applied methodology leads to good results for all of the selected events. The maximum storm surge water levels are usually higher in Cuxhaven compared to Hörnum. From visual inspection, it was found that similar results have been achieved for the rest of the observed storm surge events considered for the present study. As a result of the parameterisation of all observed storm surge events, 25 parameter time series are available for the two selected tide gauges. Each of the 25 time series consists of 314 realisations for the tide gauge of Cuxhaven and 175 realisations for the tide gauge of Hörnum.

\subsection{Monte-Carlo-Simulations}

The next step of the stochastic storm surge simulation procedure consists of fitting parametric distribution functions to the data sets resulting from the parameterisation. The distribution functions are subsequently used as a basis to run a large number of Monte-Carlo-Simulations. Table 1 contains an overview of the considered distribution functions, widely used in hydrology. In the equations, parameter $a$ denotes the location parameter (i.e. the threshold parameter for the $\mathrm{GPD}), b$ the scale parameter and $k$ the shape parameter. The maximum likelihood approach is applied to estimate the parameters (see e.g. Rao and Hamed, 2000).

All four distribution functions are fitted to the 25 parameter data sets available for the two selected tide gauges as a result of the parameterisation. The distributions that fit best to the underlying data sets are identified by calculating the RMSEs of the theoretical non-exceedance probabilities compared to the empirical non-exceedance probabilities (i.e. the plotting positions). The latter are determined following the approach proposed by Gringorten (1963) (Eq. 1), which was also used by Jensen et al. (2006) for storm surge analyses in the German Bight:

$$
\mathrm{PLP}_{\text {Gringorten }}=\frac{i-0.44}{N+0.12}
$$

where PLP $_{\text {Gringorten }}$ is the probability that a given value is less than the $i$ th smallest observation in the data set consisting of $N$ observations, and $i$ is the $i$-th smallest value in the data set arranged in ascending order. An overview of alternative methods to calculate plotting positions is given by Chow (1964) and Jensen (1985). Most of the methods lead to similar results when large sample sizes are available.

Figure 9 shows the results from fitting distribution functions to the time series of selected parameters $(1,10,14$ and 23) for the tide gauges of Cuxhaven (left) and Hörnum (right). The figure shows the estimated plotting positions and the theoretical distribution functions (with $95 \%$-confidence levels) leading to the smallest RMSEs. The LogNormal distribution, for example, is the most qualified to describe the available data set for parameter 1 for the tide gauge of $\mathrm{Cux}$ haven (top, left), while the Normal distribution leads to a smaller RMSE for the tide gauge of Hörnum (top, right). For parameter 1 (i.e. the difference between the maximum storm surge water level and the water level of the first tidal low water, see Fig. 6), the observed values range between 200 and $500 \mathrm{~cm}$ for Hörnum and between 350 and $700 \mathrm{~cm}$ for Cuxhaven. For the important parameter 10, which is the maximum storm surge water level (or the highest turning point), the GPD fits best to the available data sets for both gauges. For Cuxhaven, a highest turning point of about $515 \mathrm{cmNN}$ represents a 100 -yr storm surge event, while a 100 -yr event for Hörnum has a water level of about $420 \mathrm{cmNN}$. Figure 9 shows that at least one of the considered distribution functions leads to good results for the selected parameter time series. The same is true for the other 21 parameters for both gauges. An overview of the overall results is provided by Fig. 10, where the calculated RMSEs are shown for all parameters and the tide gauges of Cuxhaven (left) and Hörnum (right). Only the results for the distribution functions leading to the smallest RMSEs are shown and the marker types denote which type of distribution was identified to fit best to the available data sets. The RMSE values are between 0.01 to $0.065 \mathrm{~cm}$ for Cuxhaven and 0.01 to $0.04 \mathrm{~cm}$ for Hörnum. No outliers are evident for both of the gauges. The slightly higher values for Cuxhaven may result from the differences in the mean tide curve compared to Hörnum or from the fact that more historical events are considered for Cuxhaven. The uncertainties in these historical events are larger.

The fitted theoretical distributions are then used with Monte-Carlo-Simulations to estimate a large number of values for each parameter. As a result, each of the parameter data sets no longer consists of 314 or 175 realisations, respectively, but of a much larger number (here 10 million to assure stability for the statistical assessment performed by Wahl et al., 2011b). Existent interdependencies between the parameters are considered by first modelling the observed interdependencies between the relative sea level parameters (which are directly or indirectly related to parameter 10) and 

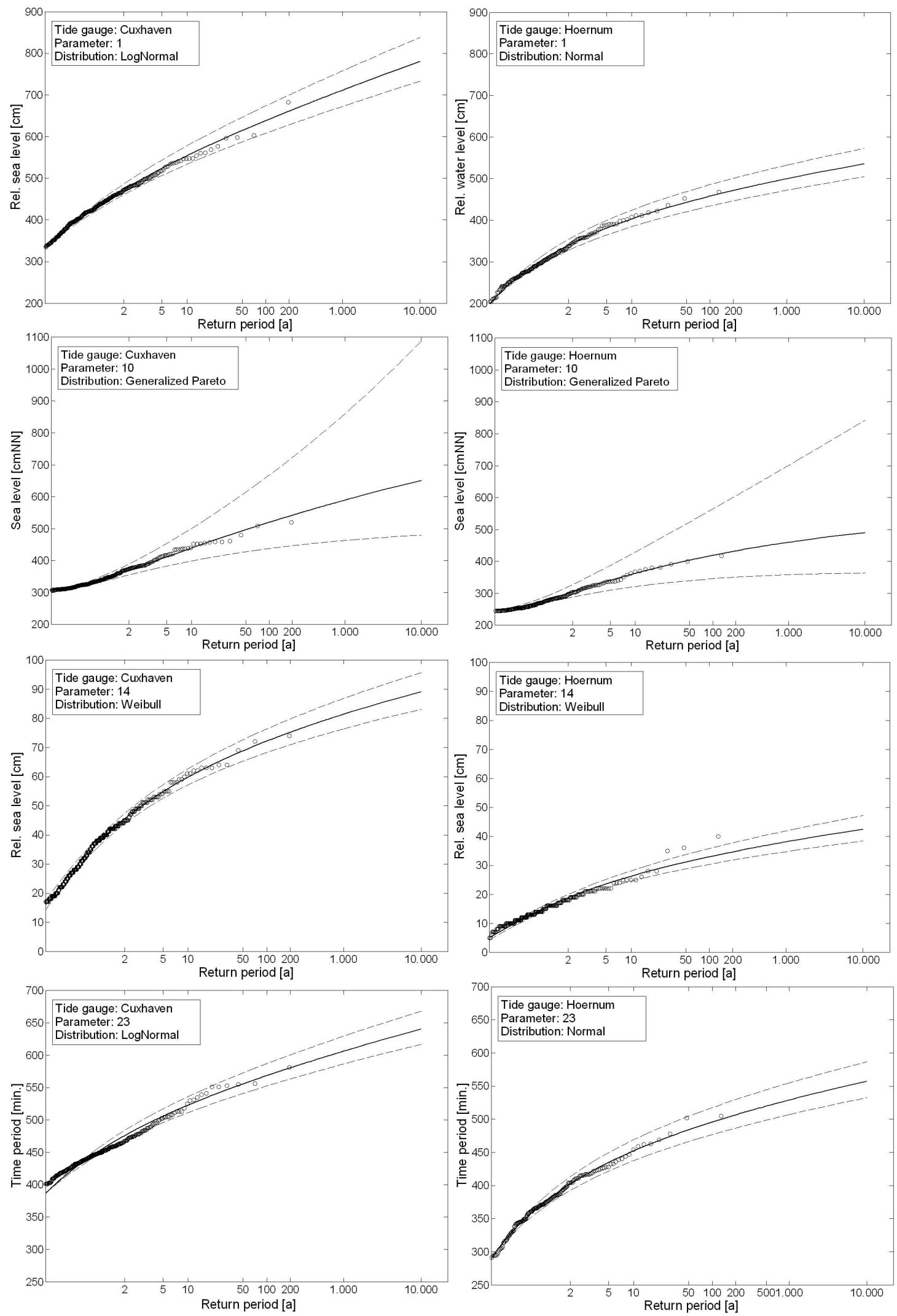

Fig. 9. Results from fitting distribution functions to selected parameter time series for the tide gauges of Cuxhaven (left) and Hörnum (right). 
parameter 10. Linear regression functions are applied to model the existing dependencies which are evident from the observed storm surge events. The slopes of the regression functions are then used to adjust the simulated results for the relative sea level parameters.

\subsection{Filter functions and model validation}

Before the model is validated, some filter functions are applied to the simulation results. Although the interdependencies between the sea level parameters are considered within the Monte-Carlo-Simulations and good results have been achieved from fitting distribution functions to the parameter time series, some inconsistencies (e.g. strongly deformed storm surge curves) occur in the results. A list of the applied filter functions with a short description and the considered threshold values is provided in Table 2. Most of these filters contribute to avoiding strong and implausible deformations of the storm surge curves and most threshold values are empirically calculated based on the observations. The filter "peak-flatness", for example, removes simulated storm surge events where flat lines occur around the peak water levels (i.e. the water level is constant for at least one hour, which usually does not happen in the German Bight area due to the prevailing tidal regime). Most of the filter functions listed in Table 2 do not affect the statistics of the simulation results. The filter function "max. water level" provides the only exception, as it removes simulated events where parameter 10 (i.e. the highest turning point) is extraordinary high and is physically implausible under current climate conditions. This may happen within the Monte-CarloSimulations when the asymptote of the distribution function fitted to parameter 10 is very large. To identify the threshold values for this filter function $(651 \mathrm{cmNN}$ for Cuxhaven and $513 \mathrm{cmNN}$ for Hörnum; see Table 2), the highest values derived in former studies based on numerical model runs or empirical analyses for the selected investigation areas have been examined. For Cuxhaven, Jensen et al. (2006) simulated a storm surge event with a maximum water level of $651 \mathrm{cmNN}$, based on a hydrodynamic model, and denoted this as the highest storm surge being physically possible under current climate conditions and based on the available data sets. The estimated uncertainty range is $603 \mathrm{cmNN}$ to $672 \mathrm{cmNN}$. Gönnert et al. (2010) derived a maximum value of $610 \mathrm{cmNN}$ for the same tide gauge from empirical studies (within the XtremRisK project). They superimposed the different storm surge components (i.e. the astronomical tide, the surge and the external surge, which is generated in the Atlantic and enters the North Sea) by considering the highest values that have been observed in the past, also taking into account the non-linear interactions between the different components. For the present study, the higher value of $651 \mathrm{cmNN}$ is used. The maximum value for the tide gauge of Hörnum derived by Jensen et al. (2006) was $489 \mathrm{cmNN}$ (I. Bork, personal communication, 2010), while Gönnert et al. (personal communication, 2011) estimated a maximum value of $513 \mathrm{cmNN}$ with the empirical approach (with an uncertainty range from $444 \mathrm{cmNN}$ to $537 \mathrm{cmNN}$ ). Again, the higher value of $513 \mathrm{cmNN}$ is considered for the present study. In summary, simulated storm surge events exceeding a water level of $651 \mathrm{cmNN}$ at the tide gauge of Cuxhaven are removed, as well as simulated storm surge events exceeding a water level of $513 \mathrm{cmNN}$ at the tide gauge of Hörnum. All of the other filter functions shown in Table 2 can be denoted as "form filters", as they contribute to avoiding strong deformations of the storm surge curves, but they do not affect the statistics. The latter is important, as stochastically simulated storm surge events are also considered for statistical analyses as presented by Wahl et al. (2011b).

Before the overall simulation results are presented and discussed in the following Sect. 4, the model is validated. This is done first by comparing observed and simulated dependence structures (i.e. rank correlation coefficients) between the considered 19 sea level parameters. Figure 11 shows the results for the tide gauges of Cuxhaven (left) and Hörnum (right). In the upper left triangles of the matrices, the observed interdependencies are displayed. Kendall's rank correlation $\tau$, a well known non-parametric measure of dependence, is calculated for all parameter pairs following Eq. (2) (e.g. Kendall, 1938; Karmakar and Simonovic, 2009):

$\tau=\left(\begin{array}{l}n \\ 2\end{array}\right)^{-1} \sum_{i<j} \operatorname{sign}\left[\left(x_{i}-x_{j}\right)\left(y_{i}-y_{j}\right)\right]$

where sign $=1$ if $\left[\left(x_{i}-x_{j}\right)\left(y_{i}-y_{j}\right)\right]>0$ and sign $=-1$ if $\left[\left(x_{i}-x_{j}\right)\left(y_{i}-y_{j}\right)\right]<0$, with $i, j=1,2, \ldots, n$. For the pairs with values for $\tau$ larger or equal $0.3[-]$, the actual calculated values for $\tau$ are shown in the upper left triangles of the matrices displayed in Fig. 11. For the parameter pairs where the values of $\tau$ are smaller than 0.3 [-], it is assumed that no significant correlation exists (e.g. Degen and Lohrscheid, 2002) and it is not expected that the model captures such weak interdependencies. For the parameter pairs for which significant correlation is evident from the observations, the values for $\tau$ are calculated based on the simulation results and displayed in the lower right triangles of the matrices shown in Fig. 11. The relationship between parameter 10 and the other sea level parameters has been used to correct the simulation results as described in Sect. 3.2. Hence, all values for $\tau$ calculated between parameter 10 and the other sea level parameters are written in the matrices. For both gauges, no significant interdependencies are evident from the observations for most of the parameter pairs. For those pairs where large values of $\tau$ (i.e. $\tau \geq 0.3$ only significant positive correlation is evident in the data sets) are calculated based on the observations similar values for $\tau$ are also derived from the simulation results. Only very few parameter pairs show significant correlation in the observed data sets, while almost no correlation is evident from the simulation results (e.g. the pair (12|13) for Cuxhaven or the pair (7|8) for Hörnum). These 

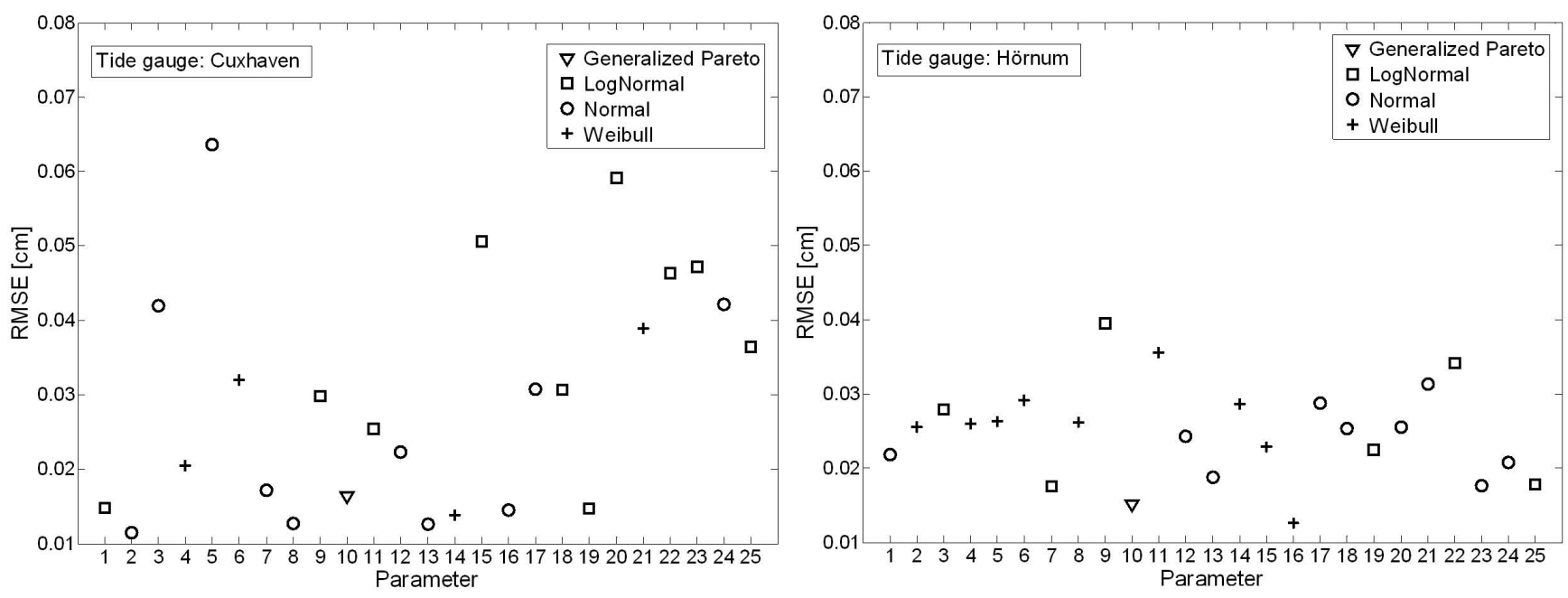

Fig. 10. RMSE values calculated after fitting distribution functions to the 25 parameter time series of the tide gauges of Cuxhaven (left) and Hörnum (right) (only the values for the distribution functions with the smallest RMSEs are shown).

Table 2. Filter functions considered for the present study to avoid inconsistencies in the simulation results.

\begin{tabular}{|c|c|c|}
\hline Abbreviation & Description & Threshold \\
\hline max. water level & $\begin{array}{l}\text { exceedance of the maximum storm } \\
\text { surge water level currently considered } \\
\text { physically possible }\end{array}$ & $\begin{array}{l}\text { Cuxhaven: } 651 \mathrm{cmNN} \\
\text { Hörnum: } 513 \mathrm{cmNN}\end{array}$ \\
\hline surrounding peaks & $\begin{array}{l}\text { first and third tide are higher than sec- } \\
\text { ond tide }\end{array}$ & $\begin{array}{l}\text { Cuxhaven: } 0 \mathrm{~cm} \\
\text { Hörnum: } 0 \mathrm{~cm}\end{array}$ \\
\hline peak-flatness & $\begin{array}{l}\text { difference of the water level one hour } \\
\text { before/after a peak (high or low water) } \\
\text { and the peak water level itself is very } \\
\text { small (i.e. almost a flat line) }\end{array}$ & $\begin{array}{l}\text { Cuxhaven: } 1 \mathrm{~cm} \\
\text { Hörnum: } 1 \mathrm{~cm}\end{array}$ \\
\hline peak-steepness & $\begin{array}{l}\text { difference of the water level one hour } \\
\text { before/after a peak (high or low water) } \\
\text { and the peak water level itself is very } \\
\text { large }\end{array}$ & $\begin{array}{l}\text { Cuxhaven: } 112 \mathrm{~cm}^{*} \\
\text { Hörnum: } 59 \mathrm{~cm}^{*}\end{array}$ \\
\hline peak-skewness & $\begin{array}{l}\text { water level one hour before a peak } \\
\text { shows a much larger/smaller difference } \\
\text { compared to the peak water level than } \\
\text { the water level one hour after the peak }\end{array}$ & $\begin{array}{l}\text { Cuxhaven: } 98 \mathrm{~cm} * \\
\text { Hörnum: } 44 \mathrm{~cm}^{*}\end{array}$ \\
\hline tidal range & tidal range is very small & $\begin{array}{l}\text { Cuxhaven: } 8 \mathrm{~cm} * \\
\text { Hörnum: } 25 \mathrm{~cm}^{*}\end{array}$ \\
\hline low water evolution & $\begin{array}{l}\text { second low water is smaller than the } \\
\text { first low water or third low water is } \\
\text { smaller than fourth low water }\end{array}$ & $\begin{array}{l}\text { Cuxhaven: } 0 \mathrm{~cm} \\
\text { Hörnum: } 0 \mathrm{~cm}\end{array}$ \\
\hline
\end{tabular}

* Threshold values were empirically calculated based on the available observations. 

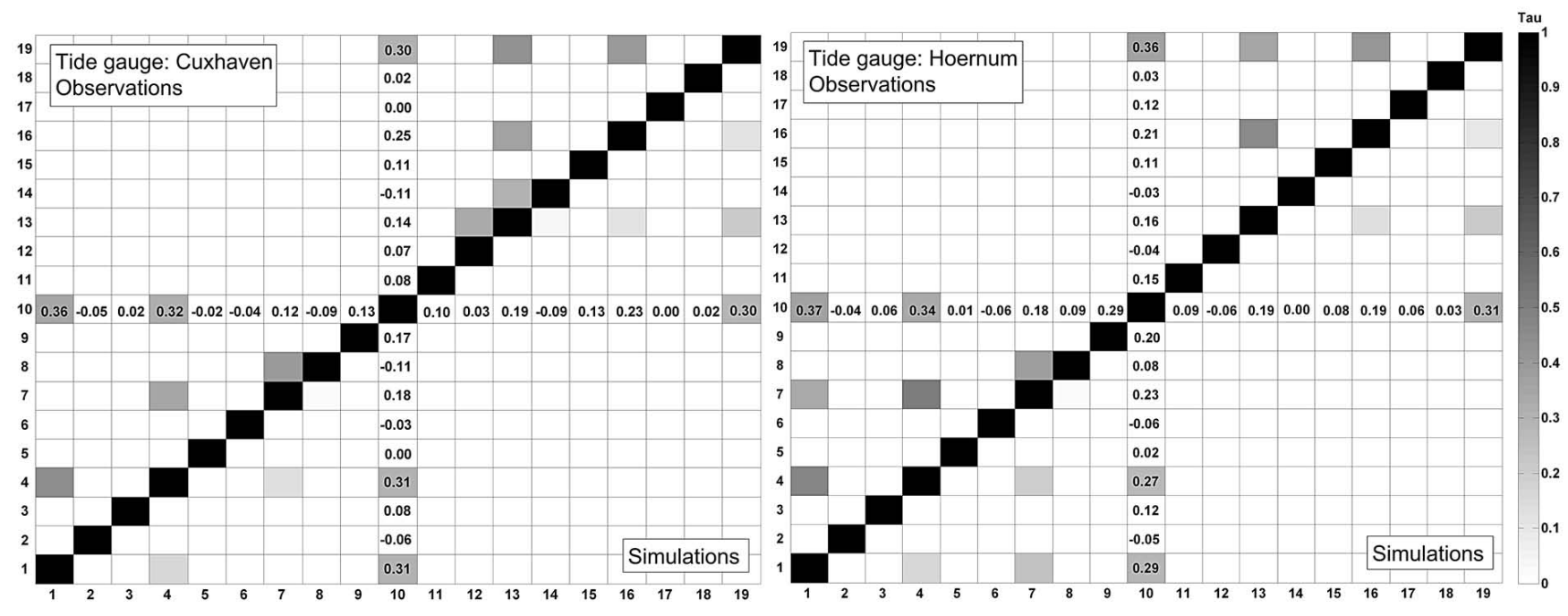

Fig. 11. Rank correlation matrices for the 19 sea level parameters from the observations (upper left triangles) and the simulation results (lower right triangles) for the tide gauges of Cuxhaven (left) and Hörnum (right). The values for $\tau$ between parameter 10 and all other parameters are written as numbers, as these relationships are considered to account for interdependencies as described in the text.
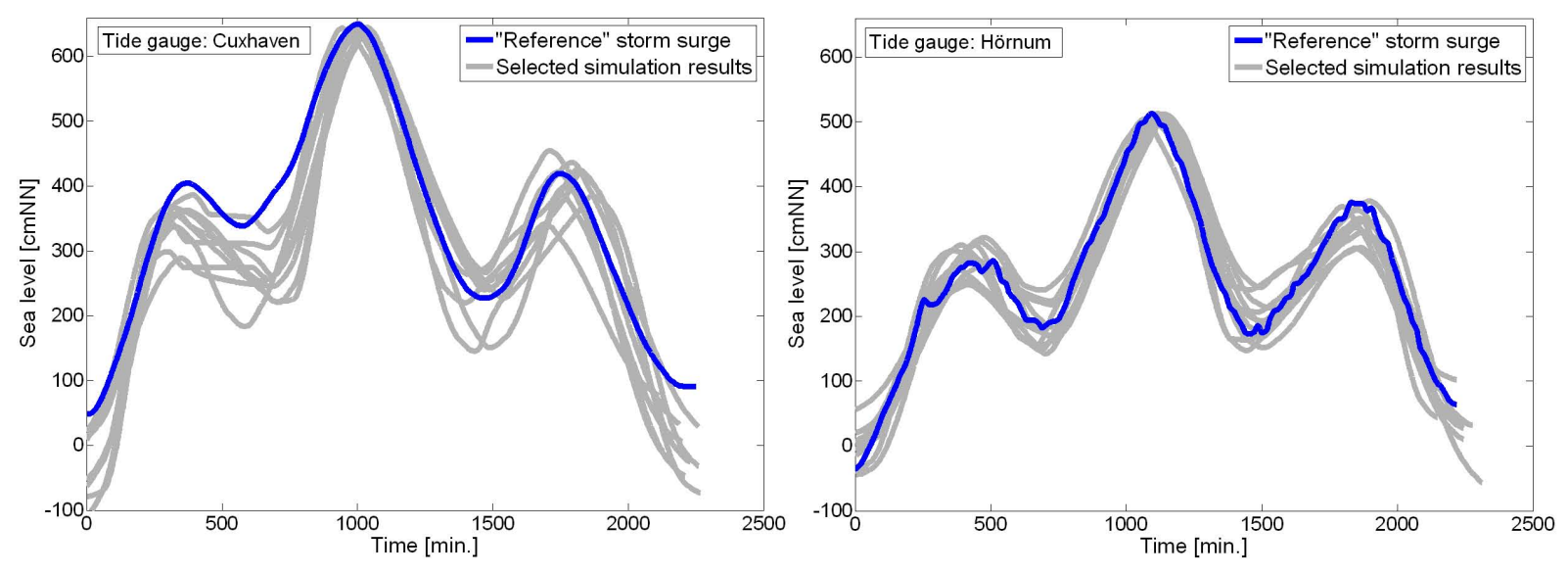

Fig. 12. Comparison of selected simulated storm surges with "reference" storm surges from former studies (left: Cuxhaven; right: Hörnum).

small differences in the rank correlation matrices do not affect the overall simulation results.

A second stage of validation was undertaken. This involved comparing selected storm surge events from the stochastic simulation with "reference storm surges". These reference events are the outcome of former studies focussing on the same investigation areas, whereas hydrodynamic models and empirical approaches were used to derive extreme storm surge events. Figure 12 shows the results for Cuxhaven (left) and Hörnum (right). The reference storm surges shown in the figure have previously been considered for the filter function "max. water level" (see Table 2). These storm surges are compared to 10 selected storm surge events from the simulation results. The reference storm surge that has been chosen for Cuxhaven (Fig. 12, left) is the outcome of a three year research project aimed at determining the highest storm surge water levels that are physically plausible and may occur along the German North Sea coastline under current climate conditions (see Jensen et al., 2006). A range of extreme (but physically consistent) weather conditions were considered to force a hydrodynamic model. The storm surge event, which is used here as a reference event, was the highest one derived. From Fig. 12 (left), it is obvious that the selected stochastically simulated storm surge curves are very similar to the reference event. Only the peak water levels of the initial tides are slightly smaller in the simulations compared to the reference storm surge. This is due to the fact that the second tidal low water (i.e. the absolute 


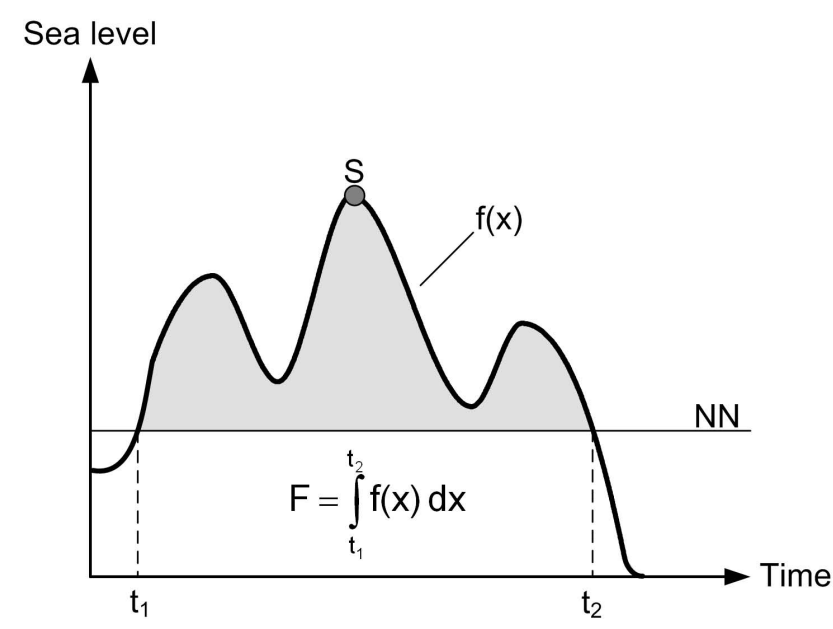

Fig. 13. Definition of the storm surge intensity as considered for the present study.

water level of parameter 7) is very high compared to the first high water (i.e. the absolute water level of parameter 4) in the reference storm surge. This is not typical for storm surges in Cuxhaven and thus only a few events showing this phenomenon are available from the simulated results. Furthermore, the selected reference storm surges (for Cuxhaven, as well as for Hörnum) are very extreme events and hence, only few storm surges with similar highest turning points (i.e. parameter 10) are simulated. The reference event for Hörnum is the result of extensive empirical analyses recently conducted by Gönnert et al. (2010 and personal communication). Different surge components were analysed separately and superimposed (by considering the non-linear interaction) to construct extreme storm surge events. Figure 12 (right) shows that the character of the reference storm surge event is fully resolved by the 10 stochastically simulated storm surges. Overall, the findings from the model validation presented in Figs. 11 and 12 highlight that the applied methodology to stochastically simulate storm surge scenarios leads to reasonable and reliable results compared to other methods (e.g. hydrodynamic modelling or empirical studies) that can be used to derive storm surge scenarios.

\section{Results and discussion}

To present the overall results from the stochastic storm surge simulation (i.e. 10 mio. synthetic and high frequency storm surge scenarios), the two important storm surge parameters "highest turning point" $(S)$ and "intensity" $(F)$ are taken into account. The parameter 'highest turning point' represents the maximum water level during a storm surge event. As described in Sect. 1, taking only this parameter into account is not sufficient for risk analyses where the complete storm surge curve has to be considered for e.g. breach modelling or calculation of potential losses in the hinterland. Therefore, the additional parameter "intensity" is introduced in Fig. 13 (in Germany this parameter is also known as "fullness"). The intensity of a storm surge represents the area between the observed storm surge water level and a given threshold (here: the German ordnance datum NN, which nowadays is approximately $15 \mathrm{~cm}$ a.m.s.l. height). Therefore, it serves as a proxy for the energy input into the existing coastal defence structures during storm surge events. The combined analysis of the two storm surge parameters $S$ and $F$ firstly allows for presenting the overall simulation results and secondly, the characteristic of a storm surge curve is well represented by these two parameters. Thus, Wahl et al. (2011b) present a multivariate statistical approach to consider these two parameters also for the statistical assessment of storm surge events within risk analyses.

The stochastic simulation results are shown in Fig. 14 for Cuxhaven (top) and Hörnum (bottom) (the unit of the intensity was divided by 1000 for plotting purposes). In both subplots, the observed storm surge events, represented by the parameters $S$ and $F$ and shown as black dots, are enclosed by the simulation results shown as grey dots. Both data sets (i.e. observed and simulated) show a similar structure of dependence. One million of the simulated events are shown in the figure for presenting purposes. Envelopes from all 10 million simulated events are also displayed. For both gauges, none of the observed events exceeds the estimated envelopes and the rank correlation (Kendall's $\tau$ ) is found to be $\tau=0.43[-]$ for the observations (for both gauges) and $\tau=0.44[-]$ and $\tau=0.45[-]$ for the simulation results for Cuxhaven and Hörnum, respectively. This highlights that the stochastic storm surge model leads to reasonable results.

The generated data sets may be used for various future applications, as for example, as a basis for statistical assessments as presented by Wahl et al. (2011b). Selected storm surge scenarios, as shown in Fig. 14 (right), can directly be considered as input data for integrated risk analyses, contributing to a reliable approximation of a risk curve as shown in Fig. 2 (left). The simulated storm surge scenarios displayed in Fig. 14 (right) all have the same "highest turning points" for the particular tide gauges, while having significantly different "intensities". This also affects the potential damages along the coastal defence line and in the hinterland; it could be expected that the estimated losses caused by the selected storm surge events are considerably different. As each of the grey dots in the figure represents a storm surge event which is available as a time series with a 1-min resolution, it is easily possible to extract a large number of scenarios showing different characteristics and being relevant for a risk analysis at the same time (see also Fig. 2). By applying the stochastic model it is possible to provide accurate hydrodynamic boundary conditions for risk assessments in coastal areas. Considering the stochastic model in combination with few numerical model runs or empirical analyses improves the accuracy of the overall results while the required 

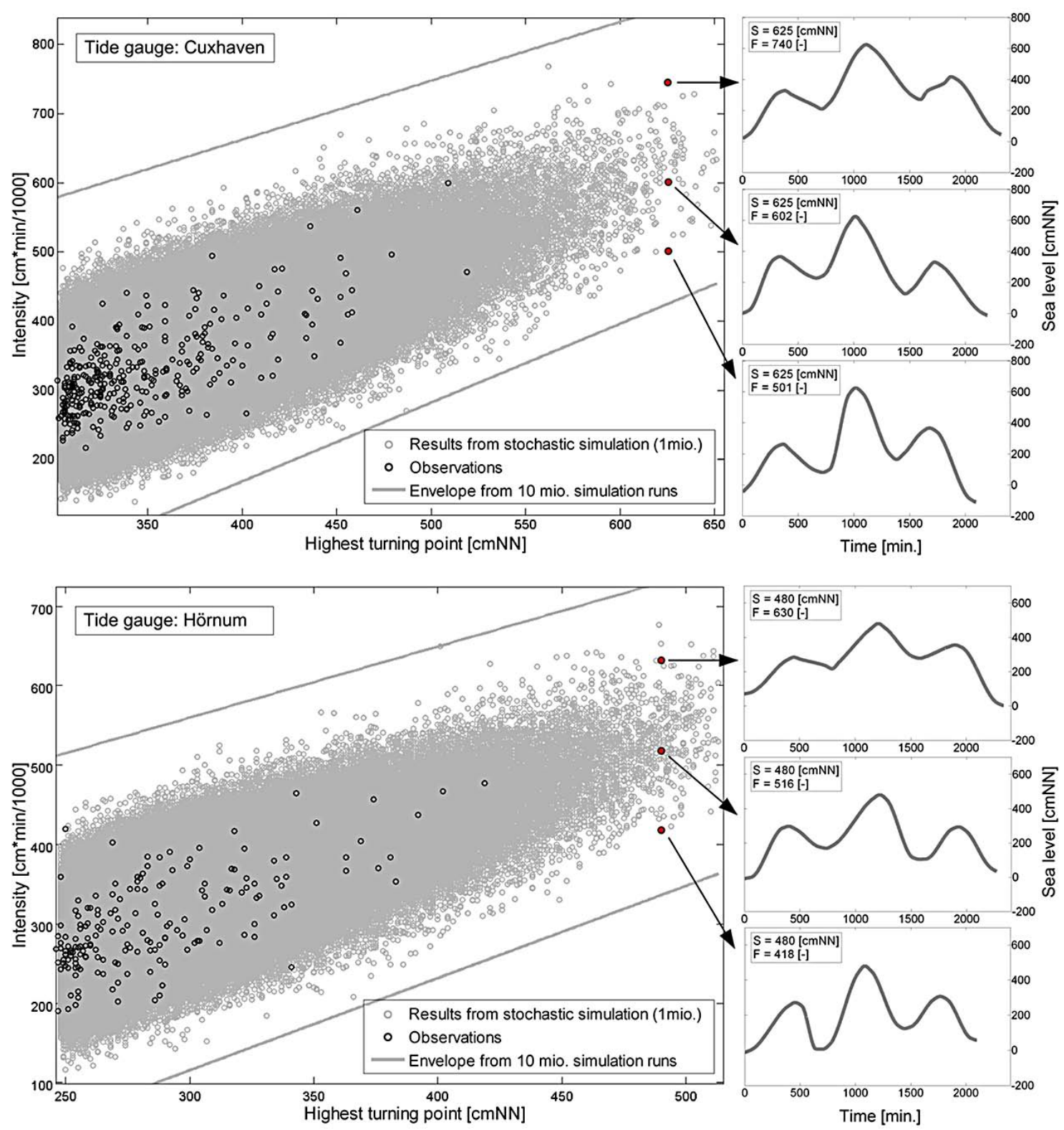

Fig. 14. Results from simulating 10 million storm surges, represented by the parameters "highest turning point" and "intensity" for the tide gauges of Cuxhaven (top) and Hörnum (bottom) and selected high resolution and stochastically simulated storm surge curves (right).

computation time is relatively short. High frequency storm surge curves (at least hourly sea level observations) represent the only input data required to run the model. In addition, some information about the physically possible extreme water levels (under current climate conditions) should be taken into account. The model also allows the consideration of possible future sea level changes within the simulations.

\section{Conclusions}

In this paper, a stochastic storm surge model which simulates a large number of storm surge scenarios is described in detail. The storm surge scenarios may be used as input data for various practical and research-oriented applications. The most important steps of the stochastic simulation consist in: (i) parameterising the observed events, (ii) fitting parametric distributions functions to the resulting parameter time series, and (iii) applying empirical filter functions (see Sect. 3). The methodology leads to reliable results and is at the same time very cheap in computation time, compared 
to alternative methods that can be applied to derive a larger number of storm surge scenarios. The skills of the model have been highlighted in the validation section (Sect. 3.3) by comparing the simulation results with the observations and results from former studies based on hydrodynamic models or empirical analyses. The two important storm surge parameters "highest turning point" and "intensity" are considered to present the overall simulation results and to characterise a particular storm surge event. This means that the temporal evolution of extreme water levels is (at least implicitly) taken into account in addition to the maximum water level. The latter is the only parameter that has been analysed in most former studies but is not sufficient to perform integrated risk analyses (e.g. based on the Source-Pathway-Receptor Concept). By plotting the two parameters as shown in Fig. 14, it is easily possible to extract a specified number of storm surge scenarios with different characteristics from the simulation results, whereas every synthetic storm surge event is available as a time series with a 1-min resolution. These storm surge curves can directly be considered for scenario- based risk analyses in coastal areas. They contribute to reducing the uncertainties and improving the overall results.

In addition, the simulated storm surge events can be employed for statistical analyses. Wahl et al. (2011b) apply a multivariate statistical model based on Archimedean Copula functions to estimate the exceedance probabilities of storm surge scenarios. They consider the results from the present study as the data basis and they also take into account the two storm surge parameters "highest turning point" and "intensity" to derive joint exceedance probabilities. This is a major step forward when calculating exceedance probabilities for storm surge scenarios within risk analyses. An approach to extend the bivariate Copula model to the trivariate case is also presented. This allows selected wave parameters in addition to the two storm surge parameters to be taken into account.

Acknowledgements. We thank our project partners from the XtremRisK project (i.e. colleagues from the Universities of Braunschweig and Hamburg-Harburg and from the Agency of Roads, Bridges and Waters in Hamburg) for a pleasant and trustful cooperation and for providing very helpful comments on our work. The XtremRisK project is funded by the German Federal Ministry of Education and Research (BMBF) through the project management of Projektträger Jülich (PTJ) under the grant number 03F043B. Data sets were provided by the Shipping Administration of the Federal Government (WSA). Ivan Haigh and an anonymous reviewer provided professional and valuable comments on a draft version of this paper.

Edited by: D. Rybski

Reviewed by: I. Haigh and another anonymous referee

\section{References}

Ang, A. H.-S. and Tang, W. H.: Probability Concepts in Engineering - Emphasis on Application in Civil \& Environmental Engineering, Wiley, 2nd Edn., ISBN: 978-0-471-72064-5, 2007.

Bender, J. and Jensen, J.: Generierung synthetischer Hochwasserganglinien, Tagungsband des 1. CoastDoc-Seminars, in: Mitteilungen des Forschungsinstituts Wasser und Umwelt, Vol. 2, ISSN 1868-6613, 2011.

Burzel, A., Dassanayake, A., Naulin, M., Kortenhaus, A., Oumeraci, H., Wahl, T., Mudersbach, C., Jensen, J., Gönnert, G., Sossidi, K., Ujeyl, G., and Pasche, E.: Integrated flood risk analysis for extreme storm surges, Proceedings of the 32nd International Conference on Coastal Engineering, Shanghai, China, 2010.

Cai, Y., Gouldby, B. P., Hawkes, P. J., and Dunning, P.: Statistical simulation of flood variables: incorporating short-term sequencing, J. Flood Risk Manage., 1, 3-12, 2008.

Chow, V. T.: Handbook of Applied Hydrology, McGraw-Hill Book Company, 1964.

Coles, S.: An Introduction to Statistical Modeling of Extreme Values, Springer, ISBN 1-85233-459-2, 2001.

Degen, H. and Lohrscheid, P.: Statistik-Lehrbuch, mit Wirtschaftsund Bevölkerungsstatistik, 2. Auflage, Oldenbourg Wissenschaftsverlag, ISBN 3-486-27240-3, 2002.

EU: Directive 2007/60/EC of the European parliament and of the council of 23 October 2007 on the assessment and management of flood risks, 2007.

FLOODsite: Integrated Flood Risk Analysis and Management Methodologies, available at: http://www.floodsite.net last access: 19 August 2011), 2009.

Gönnert, G., Buß, Th., and Thumm, S.: Coastal Protection in Hamburg due to climate change - An example to design an extreme storm surge event, Proc. of the First International Conference "Coastal Zone Management of River Deltas and Low Land Coastlines", Alexandria, Egypt, 2010.

Gringorten, I. I.: A plotting rule for extreme probability paper, J. Geophys. Res., 68, 813-814, 1963.

Jensen, J.: Über instationäre Entwicklungen der Wasserstände an der Deutschen Nordseeküste, Mitteilungen des LeichtweißInstituts für Wasserbau der Technischen Universität Braunschweig, Technische Universität Braunschweig, 88, 1985.

Jensen, J., Mudersbach, Ch., Bork, I., Müller-Navarra, S. H., Koziar, Ch., and Renner, V.: Modellgestützte Untersuchungen zu Sturmfluten mit sehr geringen Eintrittswahrscheinlichkeiten an der Deutschen Nordseeküste, Die Küste, Heft 71, Boyens Medienverlag, Heide i., Holstein, 2006.

Kahaner, D., Cleve M., and Nash, S.: Numerical Methods and Software, Prentice Hall, 1988.

Karmakar, S. and Simonovic, S. P.: Bivariate flood frequency analysis: Part 2 - a copula-based approach with mixedmarginal distributions, J. Flood Risk Manage., 1, 190-200, 2009.

Kendall, M.: A New Measure of Rank Correlation, Biometrika, 30, 81-89, doi:10.1093/biomet/30.1-2.81, 1938.

Klein, B.: Ermittlung von Ganglinien für die risikoorientierte Hochwasserbemessung von Talsperren, PhD thesis, Schriftenreihe Hydrologie \& Wasserwirtschaft Ruhr- Universität Bochum, Vol. 25, 2009.

Lang, M., Ouarda, T. B. M. J., and Bobee, B.: Towards operational guidelines for over-threshold modelling, J. Hydrol, 225, 
103-117, 1999.

McGranahan, G., Balk, D., and Anderson, B.: The rising tide: assessing the risks of climate change and human settlements in low elevation coastal zones, Environ. Urban., 19, 17-37, 2007.

Mudersbach, C. and Jensen J.: Extremwertstatistische Analyse von historischen, beobachteten und modellierten Wasserständen an der deutschen Ostseeküste, Die Küste, Heft 75, Boyens Medienverlag, Heide i., Holstein, 2009.

Mudersbach, C., Wahl, T., Haigh, I. D., and Jensen, J.: Trends in extreme high sea levels along the German North Sea coastline compared to regional mean sea level changes, Cont. Shelf Res., in review, 2011.

Nicholls, R. J., Marinova, N., Lowe, J. A., Brown, S., Vellinga, P., de Gusmão, D., Hinkel, J., and Tol, R. S. J.: Sea-level rise and its possible impacts given a "beyond $4^{\circ} \mathrm{C}$ world" in the twenty-first century, Phil. Trans. R. Soc. A., 369, 161-181, doi:10.1098/rsta.2010.0291, 2011.

Oumeraci, H.: Sustainable coastal flood defences: scientific and modelling challenges towards an integrated risk-based design concept, Proc. First IMA International Conference on Flood Risk Assessment, IMA - Institute of Mathematics and its Applications, Session 1, Bath, UK, 9-24, 2004.

Oumeraci, H., Jensen, J., Gönnert, G., Pasche, E., Kortenhaus, A., Naulin, M., Wahl, T., Thumm, S., Ujeyl, G., Gershovich, I., and Burzel, A.: Flood Risk Analysis for a Megacity: The German XtremRisK-Project, European and Global Communities combine forces on Flood Resilient Cities, Paris, France, 2009.
Rao, A. R. and Hamed, K. H.: Flood frequency analysis, CRC Press, New York, 2000.

Reeve, D.: Risk and Reliability: Coastal and hydraulic engineering, Spon Press, ISBN: 978-0-415-46755-1, 2010.

Schumann, A.: Hochwasserwahrscheinlichkeiten in Theorie und Praxis, in: Forum für Hydrologie und Wasserbewirtschaftung; Herausgeber: Blöschl und Merz, Heft 30.11, ISBN: 978-3941897-79-3, 2011.

Wahl, T., Jensen, J., and Frank, T.: On analysing sea level rise in the German Bight since 1844, Nat. Hazards Earth Syst. Sci., 10, 171-179, doi:10.5194/nhess-10-171-2010, 2010a.

Wahl, T., Jensen, J., and Mudersbach, C.: A multivariate statistical model for advanced storm surge analyses in the North Sea, Proceedings of the 32nd International Conference on Coastal Engineering, Shanghai, China, $2010 \mathrm{~b}$.

Wahl, T., Jensen, J., Frank, T., and Haigh, I. D.: Improved estimates of mean sea level changes in the German Bight over the last 166 years, Ocean Dynam., 61, 701-715, doi:10.1007/s10236-0110383-x, 2011a.

Wahl, T., Mudersbach, C., and Jensen J.: Assessing the hydrodynamic boundary conditions for risk analyses in coastal areas: a multivariate statistical approach based on Copula functions, Nat. Hazards Earth Syst. Sci., in review, 2011b.

Wieland, P.: Küstenfibel - Ein Abc der Nordseeküste, Westholsteinische Verlagsgesellschaft Boyens \& Co., Heide, ISBN 38042-0494-5, 1990. 